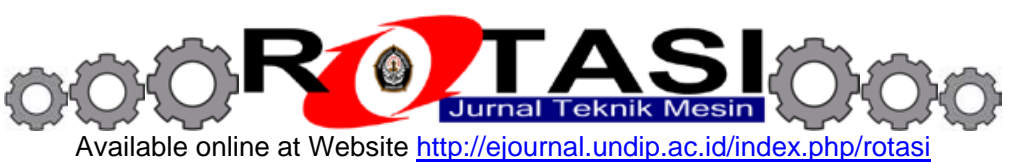

\title{
Optimalisasi Kekerasan dan Struktur Mikro Baja Karbon Sedang pada Bucket Teeth Excavator Menggunakan Metode Taguchi dan Anova
}

\author{
Budi Setiyana \\ Departemen Teknik Mesin, Fakultas Teknik, Universitas Diponegoro \\ Jl. Prof. Sudharto, SH., Tembalang-Semarang 50275, Telp. +62247460059 \\ *E-mail: bsetiyana@yahoo.com
}

\begin{abstract}
Abstrak
Bucket teeth excavator merupakan bagian dari excavator yang sering mengalami keausan dan patah dimana umunya menggunakan material baja karbon sedang. Pada penelitian kali ini, material yang digunakan adalah baja AISI 1045 dengan unsur karbon 0,48\% dan cara untuk meningkatkan sifat mekanisnya dengan melakukan proses heat treatement. Metode Taguchi digunakan untuk mendapatkan heat treatment terbaik dengan variasi percobaan berupa temperatur hardening, quenching, tempering dan waktu penahanannya, sedangkan metode ANOVA digunakan untuk mengetahui pengaruh heat treatment terhadap materialnya. Hasil dari kombinasi percobaan didapatkan heat treatment terbaik dengan hardening $845^{\circ} \mathrm{C}$, media quenching air, tempering $200^{\circ} \mathrm{C}$ dengan waktu penahanan 60 menit. Hasil nya terjadi peningkatan nilai kekerasan dari 25 HRC meningkat menjadi 59,6 HRC, pada mikro strutur material telah terbentuk martensit dimana kekerasannya cukup tinggi dan keuletanya cukup baik, sementara laju keausan pada material dari $2.39036 \mathrm{E}-05 \mathrm{~mm}^{2} / \mathrm{kg}$ turun menjadi 5.37094E-06 mm²/kg. Untuk mengetahui volume yang hilang maka dilakukan uji aus dengan 100.000 kali siklus didapatkan 1.123,335 $\mathrm{mm}^{3}$ dengan kehilangan massa sebesar 7 gram. Pada pengujian perbandingan uji komposisi dan kekerasan terhadap produk yang ada dipasaran, material menggunakan baja AISI 1045 lebih baik dibandingkan dengan produk yang ada dipasaran saat ini.
\end{abstract}

Kata kunci : Bucket teeth excavator, heat treatment, AISI 1045, ANOVA, Taguchi

\section{Pendahuluan}

Dalam dunia pertambangan maupun industri infrastruktur, kita mengenal heavy equipment salah satunya excavator. Excavator adalah suatu peralatan konstruksi alat berat yang memiliki fungsi untuk melakukan pekerjaan berat seperti penggalian tanah, pengumpulan tanah, memindahkan dan mengangkut tanah serta mengangkut barangt. Pada bagian excavator terdapat bucket teeth selama ini menjadi bagian yang sering mengalami keausan hal ini berdampak pada pemakaian yang tidak terlalu lama. Bucket teeth bekerja dalam proses yang sangat kompleks bongkar muat dengan jangka waktu tertentu, dan akibatnya, baja yang digunakan untuk membuat komponen ini harus dipilih menerapkan kriteria yang seimbang antara ketangguhan dan kekerasan yang relative baik untuk menahan laju keausan agar pengeluaran biaya operasional semakin bertambah [1].

Material bucket teeth yang biasa digunakan adalah mild carbon steel dengan kandungan C sekitar 0,33 \% - 0,4\% sehingga dirasa material tersebut kurang mampu untuk menahan pembebanan dan kerasnya material yang dibebankan pada bucket teeth tersebut. Bahkan tidak jarang dijumpai di lapangan banyak bucket teeth yang mengalami abrasi atau bahkan mengalami patah saat melakukan pekerjaan yang cukup berat di lapangan.

Oleh karena itu bucket teeth harus memiliki sifat mekanis yang cukup baik agar tidak terjadi kegagalan saat excavator tersebut melakukan pekerjaanya. Salah satu cara untuk meningkatkan sifat mekanis dengan melakukan hardening dan tempering pada material. Pada metode ini dilakukan dengan mengkombinasikan dari setiap variabel yang ada kemudian diolah menggunakan metode Taguchi dan ANOVA. Metode Taguchi diusulkan pertama kali oleh Dr. Genichi Taguchi dimana peningkatan atau perbaikan kualitas dapat dicapai salah satunya dengan pengendalian kualitas yang tepat. supaya produk-produk berkualitas tinggi dapat dihasilkan dengan cepat dan dengan biaya rendah Terdapat dua pendekatan yang dapat digunakan dalam pengendalian kualitas, yaitu On-line Quality Control dan Off-line Quality Control. Salah satu metode pengendalian kualitas secara Off-line Quality Control. Sedangkan metode ANOVA digunakan untuk mengetahui pengaruh dari perlakuan yang diberikan terhadapa material. Setelah mendapatkan kombinasi percobaan metode taguchi, kemudia dilakukan kembali pengujian kekerasan, mikro struktur, dan keausan dan juga membandingkan hasilnya dengan produk di pasaran. Jika sudah memenuhi kriteria maka material pengujian bisa dikatakan berhasil dilakukan.

\section{Pemilihan Material}

\subsection{Baja Karbon Sedang AISI 1045}

Kadar karbon dalam baja jenis ini antara 0.25\%-0.60\%. Jenis baja ini biasa dibuat dalam bentuk alat-alat perkakas bagian mesin, roda gigi, pegas dan lain sebagainya. Pada aplikasinya ini baja tersebut harus mempunyai ketahanan aus yang baik karena sesuai dengan fungsinya harus mampu menahan keausan akibat bergesekan dengan 
rantai. Ketahanan aus didefinisikan sebagai ketahanan terhadap abrasi atau ketahanan terhadap pengurangan dimensi akibat suatu gesekan [2]. Pada umumnya ketahanan aus berbanding lurus dengan kekerasan. Baja karbon menengah dapat dilakukan perlakuan panas seperti austenisasi, quenching, dan tempering untuk meningkatkan mechanical properties. Baja karbon sedang yang digunakan pada penelitian ini yaitu baja AISI 1045. Berikut ini pada Tabel 1. merupakan komposisi kimia dari baja AISI 1045.

Tabel 1. Komposisi material AISI 1045 (\%)

\begin{tabular}{ccccccccc}
\hline $\mathrm{Fe}$ & $\mathrm{C}$ & $\mathrm{Si}$ & $\mathrm{Cu}$ & $\mathrm{Mn}$ & $\mathrm{P}$ & $\mathrm{Cr}$ & $\mathrm{S}$ \\
\hline 92,41 & 0,48 & 0,27 & 0,0261 & 0,65 & 0,017 & 0,003 & 0,0108 \\
\hline
\end{tabular}

\section{Metode Penelitian}

Tahapan dalam penelitian ini adalah menentukan kombinasi percobaan dengan proses heat treatment dan menganalisa menggunakan metode Taguchi dan ANOVA menggunakan software Minitab 17. Kemudian mempersiapkan spesiemn baja AISI 1045. Hasil kombinasi yang didapat akan diuji kembali seperti, uji kekerasan, uji mikro struktur, uji keausan, dan komposisi. Hal ini mengacu pada diagram alir sebagaimana tercantum pada Gambar 1.


Gambar 1. Diagram alir penelitian

\subsection{Menentukan Variabel dan Perancangan Desain}

Variabel penelitian dilakukan dengan tiga taraf, yaitu suatu proses perlakuan disekitar kondisi terbaik dan masih dalam batas standar ditentukan. Penentuan variabel ini diambil dari beberapa eksperimen yang pernah dilakukan yang ditunjukan pada table 1 .

Tabel 2. Variabel penelitian

\begin{tabular}{cccc}
\hline \multirow{2}{*}{ Faktor } & \multicolumn{3}{c}{ Taraf } \\
\cline { 2 - 4 } & 1 & $845^{\circ} \mathrm{C}$ & 3 \\
\hline Hardening & $820^{\circ} \mathrm{C}$ & Oli & $860^{\circ} \mathrm{C}$ \\
Quenching & Air & $200^{\circ} \mathrm{C}$ & Air Garam \\
Tempering & $150^{\circ} \mathrm{C}$ & $250{ }^{\circ} \mathrm{C}$ & 90 menit \\
Holding time & 30 menit & 60 menit & 90 \\
\hline
\end{tabular}


Setelah menentukan variabel yang dipakai, setiap variabel akan dilakukan kombinasi secara random kedalam kolom ortogonal array dengan menggunakan metode Taguchi pada software Minitab 17 seperti Gambar 2.

\begin{tabular}{|r|r|r|r|r|}
\hline+ & C1 & C2 & C3 & \multicolumn{1}{c|}{ C4 } \\
\hline & A & B & C & D \\
\hline 1 & 1 & 1 & 1 & 1 \\
\hline 2 & 1 & 2 & 2 & 2 \\
\hline 3 & 1 & 3 & 3 & 3 \\
\hline 4 & 2 & 1 & 2 & 3 \\
\hline 5 & 2 & 2 & 3 & 1 \\
\hline 6 & 2 & 3 & 1 & 2 \\
\hline 7 & 3 & 1 & 3 & 2 \\
\hline 8 & 3 & 2 & 1 & 3 \\
\hline 9 & 3 & 3 & 2 & 1 \\
\hline
\end{tabular}

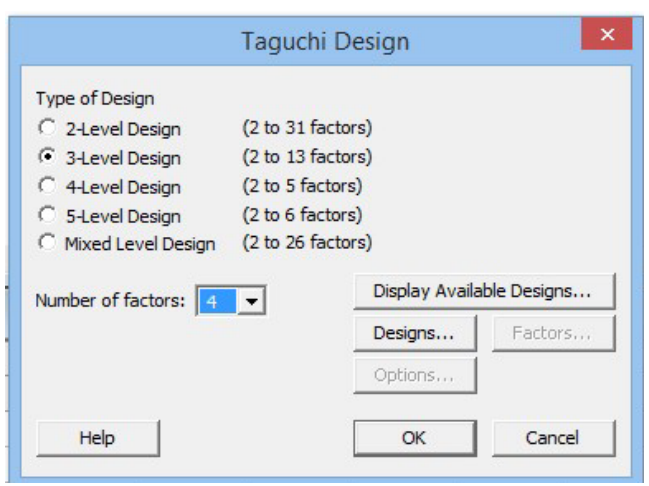

Gambar 2. Variasi percobaan Ortogonal array

\subsection{Pelaksanaan eksperimen}

Mempersiapkan 9 spesimen yang masing-masing memiliki perlakuan secara berbeda. Spesimen akan melewati tahapan proses hardening dengan temperature $820^{\circ} \mathrm{C}, 854^{\circ} \mathrm{C}, 860^{\circ} \mathrm{C}$ masing-masing ditahan selama 20 menit yang dimasukan kedalam tungku furnance. Diikuti dengan pendinginan cepat proses quenching menggunakan media pendinginan masing-masing, air, oli, dan air garam. Selanjtnya melewati proses tempering melewati proses quenching kemudian dilakukan proses tempering dengan masing-masing temperature $150^{\circ} \mathrm{C}, 200^{\circ} \mathrm{C}, 250^{\circ} \mathrm{C}$ dan waktu penahan yang berbeda yaitu, 30 menit, 60 menit, 90 menit.

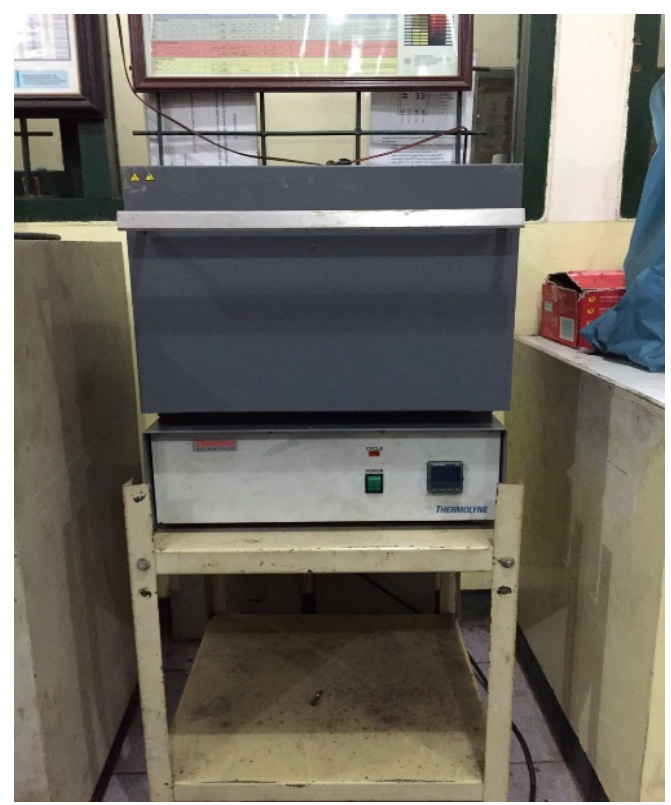

Gambar 3. Furnance chamber

Setelah melalui proses heat treatment kemudian .Setelah dilakukan proses perlakuan panas kemudian dilanjutkan dengan pengujian kekerasan dengan menggunakan alat Rockwell Hardness Tester. Hasil dari uji kekerasan dimasukan kedalam kolom ortogonal array dari setiap variabel untuk menetukan ANOVA dan SNR seperti Gambar 2.

\subsection{Mencari ANOVA (Analysis of Variance)}

Setelah melakukan heat treatment dan mendapatkan hasilnya, tahap selanjutnya melakukan analisis varian.

Tahapan analisis yang digunakan dalam tulisan ini adalah:

1. Menentukan pula hipotesis nol $\left(\mathrm{H}_{0}\right)$ dan hipotesis alternatif $\left(\mathrm{H}_{1}\right)$.

2. Menghitung variabilitas dari seluruh sampel.

3. Menghitung derajat kebebasan (degree of freedom)

4. Menghitung varian antar kelompok dan variance dalam kelompok

5. Menghitung nilai distribusi $\mathrm{F}$ ( $\mathrm{F}_{\text {hitung}}$ ) berdasarkan perbandingan varian antar kelompok dan varian dalam kelompok. Selain itu, F berdasarkan tabel $\left(\mathrm{F}_{\text {tabel }}\right)$ juga dihitung, berdasarkan nilai derajat kebebasan (langkah ke-3) menggunakan tabel distribusi-F. 
6. Uji normalitas dan homogenitas varian Jika asumsi normalitas dan homogenitas varian tidak terpenuhi, maka dilakukan transformasi.

7. Membandingkan Fhitung dengan Ftabel :

Jika $\mathrm{F}_{\text {hitung }}>$ Ftabel : tolak $\mathrm{H}_{0}$

Jika $\mathrm{F}_{\text {hitung }} \leq$ Ftabel : terima $\mathrm{H}_{0}$

8. Buat kesimpulan

\subsection{Melakukan analisis SNR (Signal Noise Ratio)}

Langkah selanjutnya menganalisa SNR dari rumus sebagai berikut:

$$
\mathrm{S} / \mathrm{N}=-10 \times \log \left[\sum \frac{\left(\frac{1}{\gamma^{2}}\right)}{n}\right] \text {. }
$$

sehingga didapatkan faktor dengan level yang mana yang berpengaruh untuk mengurangi noise dan mendapatkan hasil rancangan yang optimal.

\subsection{Penentuan Kondisi Optimum}

Kondisi Optimum dapat diperoleh dengan memilih nilai rata-rata SN Ratio dari level yang memberikan nilai terbesar untuk setiap respon.

\subsection{Pengujian}

Setelah diketahui hasil kombinasi yang optimum, tahap selanjutnya melakukan pengujian kembali untuk membandingkan dari raw materail dengan hasil yang telah didaptkan agar sesuai dari tujuan mengoptimalisasikan sifat meakni material tersebut.

Pengujian kekerasan pada peneliitan ini menggunakan metode kekerasan Rockwell dengan alat uji kekerasan Rockwell Hardness Tester HR-150A dengan menggunakan skala C (HRC) yang mana pada skala tersebut memiliki pembebanan 150 kgf dengan menggunakan indentor intan. Pengujian speciemn sebelum dan hasil di heat treatment dari nilai optimum diuji pada 3 titik berbeda. Pengujian ini berdasarkan standar ASTM E18 [3]. Lalu hasil pengujian kekerasan dibandingkan dengan produk di pasaran agar diketahui apakah sudah memenuhi standar bahkan melebihi.

Pengujian struktur mikro dilakukan bertujuan untuk mengetahun butir dari raw material, setelah di hardening, dan tempering. Pengujian ini menggunakan mikroskop merk Olympus BX41M dengan perbesaran 200x. specimen untuk pengujian struktur mikro terlebih dahulu dilakukan proses pemolesan dengan amplas dan autosol kemudian dilakukan pengetsaan dengan larutan 2,5 ml HNO3 dan 100 ml Etanol [4].

Pengujian keausan dibagi menjadi dua pengujian yaitu plate on disk dan pin on disk. pengujian plate on disk dilakukan dengan metode Ogoshi dengan alat Universal Speed Testing Type OAT-U. Pengujian ini dilakukan dengan pembebanan 6,36 kg yang mana specimen digesek dengan ring penggesek untuk menimbulkan area gesekan dan dilihat dengan mikroskop perbesaran 50X untuk melihat luas area aus, setelah itu dilakukan perhitungan aus dengan memasukan persamaan [5]:

$$
W S=\frac{B \cdot b o^{3}}{8 \cdot r \cdot P o \cdot l o}
$$

Pada pengujian menggunakan pin on disk yaitu specimen dalam bentuk piringan berkontak dengan pin yang diberi pembebanan 500 gram dalam jangka 100.000 kali putaran. Pengujian ini berdasrkan standar ASTM G99 untuk perhitungan volume yang hilang dengan persamaan [6] :

$$
\text { V loss }=2 \pi R\left[r^{2} \sin ^{-1}(d / 2 r)-(4 / d)\left(4 r^{2}-d^{2}\right)^{1 / 2}\right]
$$

Untuk mencari laju keausan dengan menggunakan hukum archard dengan persamaan [7]:

$$
\mathrm{k}=\frac{\text { Vloss }}{W}
$$

\section{Hasil dan Pembahasan}

\subsection{Hasil Pengujian Kekerasan}

Hasil dari masing-masing nilai kekerasan dikelompokan kedalam masing-masing sampel dapat dilihat pada Tabel 3 seperti di bawah ini. 
Tabel 3. Hasil pengujian kekerasan

\begin{tabular}{cccccccc}
\hline \multirow{2}{*}{ No. } & \multicolumn{3}{c}{ Faktor } & \multicolumn{3}{c}{ Nilai kekerasan (HRC) } \\
\cline { 2 - 7 } & Hardening & Quenching & Tempering & Holding time & $\mathbf{1}$ & $\mathbf{2}$ & $\mathbf{3}$ \\
\hline $\mathbf{1}$ & $820^{\circ} \mathrm{C}$ & Air & $150^{\circ} \mathrm{C}$ & 30 menit & 57,1 & 57 & 58,4 \\
$\mathbf{2}$ & $820^{\circ} \mathrm{C}$ & Oli & $200^{\circ} \mathrm{C}$ & 60 menit & 43,6 & 41,2 & 41,2 \\
$\mathbf{3}$ & $820^{\circ} \mathrm{C}$ & Air garam & $250^{\circ} \mathrm{C}$ & 90 menit & 43,6 & 43,3 & 46,4 \\
$\mathbf{4}$ & $845^{\circ} \mathrm{C}$ & Air & $200^{\circ} \mathrm{C}$ & 60 menit & 55,7 & 55,4 & 56,6 \\
$\mathbf{5}$ & $845^{\circ} \mathrm{C}$ & Oli & $250^{\circ} \mathrm{C}$ & 30 menit & 35,7 & 35,1 & 34,5 \\
$\mathbf{6}$ & $845^{\circ} \mathrm{C}$ & Air garam & $150^{\circ} \mathrm{C}$ & 60 menit & 58,6 & 59,4 & 59,9 \\
$\mathbf{7}$ & $860^{\circ} \mathrm{C}$ & Air & $250^{\circ} \mathrm{C}$ & 60 menit & 45,7 & 50,1 & 48,3 \\
$\mathbf{8}$ & $860^{\circ} \mathrm{C}$ & Oli & $150^{\circ} \mathrm{C}$ & 90 menit & 34,9 & 36,1 & 35,7 \\
$\mathbf{9}$ & $860^{\circ} \mathrm{C}$ & Air garam & $200^{\circ} \mathrm{C}$ & 30 menit & 55 & 58,6 & 55,4 \\
\hline
\end{tabular}

\subsection{Hasil ANOVA (Analysis of Variance)}

Berdasarkan data hasil pengukuran kekerasan pengukuran pada table 3. diatas dilakukan ANOVA untuk melihat pengaruh masing-masing parameter terhadap kekasaran permukaan. Setelah menggunakan Software Minitab 17 didapatkan hasil perhitungan dari ANOVA yang ditunjukan pada table 4. berikut ini.

Tabel 4. Hasil perhitungan ANOVA

\begin{tabular}{cccccccc}
\hline Source & DF & SS & MS & F-hitung & F-tabel & SS' & $\boldsymbol{\rho}^{\text {\% }}$ \\
\hline Hardening & 2 & 54,66 & 27,33 & 15,57 & 3,55 & 51,15 & 2,33 \\
Quenching & 2 & 1542,27 & 771,13 & 439,44 & 3,55 & 1538,76 & 70,30 \\
Tempering & 2 & 443,21 & 221,60 & 126,28 & 3,55 & 439,70 & 20,09 \\
$\quad$ Time & 2 & 116,82 & 58,41 & 33,28 & 3,55 & 113,31 & 5,17 \\
$\quad$ Error & 18 & 31,58 & 1,75 & & & & \\
$\quad$ Total & 26 & 2188,56 & & & & & \\
\hline
\end{tabular}

\subsection{Menghitung Signal Noise Ratio}

Setelah didapatkan nilai rata-rata dari uji kekerasan maka tahapan selanjutnya adalah mencari SNR (Signal Noise Ratio). SNRyang digunakan adalah larger the better (terbaik dari yang terbaik).

Tabel 5. Signal Noise Ratio

\begin{tabular}{ccccc}
\hline \multirow{2}{*}{ level } & \multicolumn{3}{c}{ Faktor } \\
\cline { 2 - 5 } & A & B & C & D \\
\hline 1 & 32,52 & 34,58 & 33,89 & 33,7 \\
3 & 33,77 & 31,45 & 34,13 & 33,84 \\
Rank & 33,21 & 34,46 & 32,48 & 33,96 \\
\end{tabular}

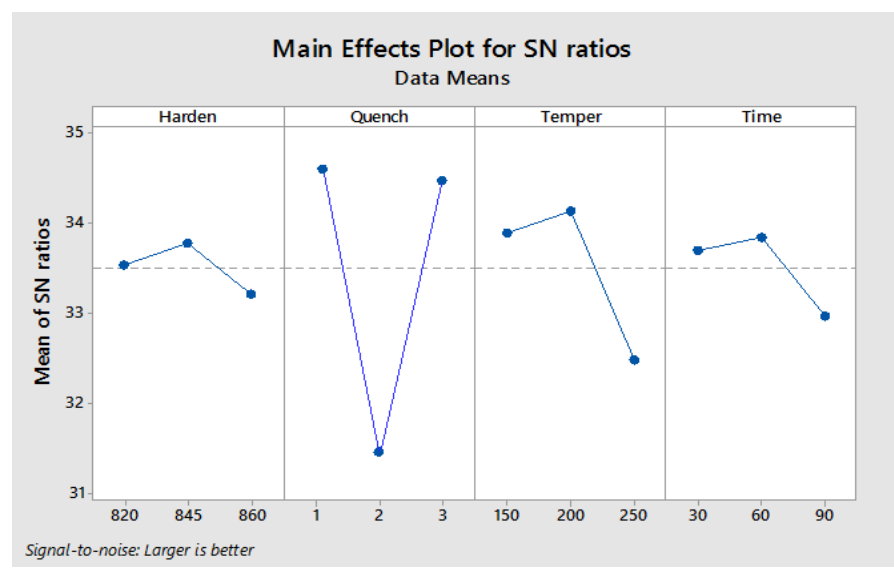

Gambar 4. SNR untuk masing-masing level pada setiap faktor 
Berdasarkan Tabel 5, faktor B merupakan faktor yang paling berpengaruh kemudia diikuti dengan faktor C, D, dan A. Untuk menentukan kondisi optimum dapat dilakukan menggunakan software Minitab 17 hasil tersebut ditunjukkan pada Gambar 4. untuk SN Ratio.

Berdasarkan gambar diatas maka dapat disimpulkan bahwa kombinasi dari setiap faktor adalah hardening dengan temperature $845^{\circ} \mathrm{C}$, quenching dengan media pendingin air, tempering dengan temperature $200^{\circ} \mathrm{C}$ dengan waktu penahan tempering 60 menit.

\subsection{Hasil Uji Komposisi}

Pengujian komposisi dilakukan menggunakan alat Spectrometer di Laboratorium ITOKOH Ceperindo, Klaten. pada Gambar 5. Berikut ini merupakan hasil dari uji komposisi yang dilakukan terhadap materail yang telah di heat treatment kembali dan produk yang ada dipasaran.

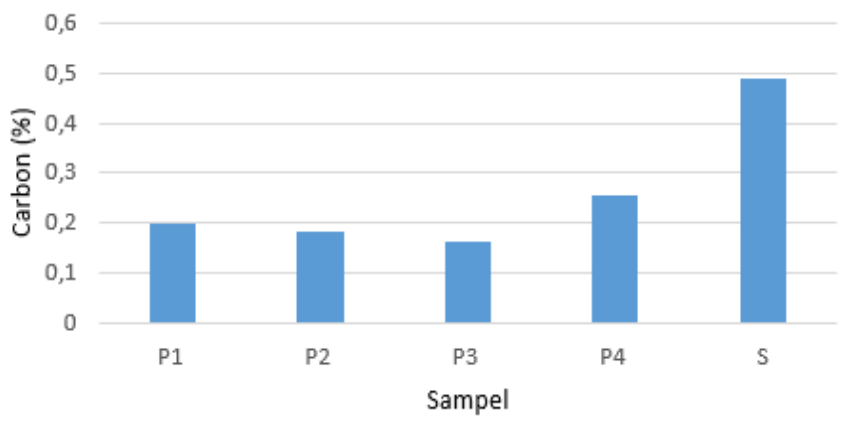

Gambar 5. Grafik perbandingan uji komposisi

Kandungan unsur karbon paling tinggi baja Spesimen yang diteliti, diikuti oleh produk diikuti bucket teeth dari produk 4, produk 1, produk 2, dan produk 3 yang ada dipasaran. Unsur karbon pada baja berperan dalam tingkat kekerasan baja, semakin tinggi nilai karbon semakin tinggi nilai kekerasannya. Pengaruh kekerasan tersebut juga berpengaruh pada kegetasan material tersebut, jadi semakin tinggi nilai kekerasan diikuti pula dengan kegetasannya.

\subsection{Hasil Uji Kekerasan}

Pada Gambar 6 merupakan hasil dari uji kekerasan yang dilakukan terhadap materail yang telah di heat treatment kembali dan produk yang ada dipasaran



Gambar 6. Grafik perbandinga uji kekerasan

Dari hasil pengujian terhadap produk bucket teeth yang ada di pasaran dan specimen yang diteliti yang telah di heat treatment yang akan digunakan untuk bucket teeth menunjukan bahwa nilai kekerasan dari specimen yang di teliti nilai kekerasanya lebih tinggi diikuti bucket teeth dari produk 3, produk 4, produk 2, dan produk 1 yang ada dipasaran dipasaran.

\subsection{Hasil Uji Mikrostruktur}

Hasil uji mikrostruktur menunjukan bahwa adanya perubahan fasa dari setiap poses heat treatment. pada Gambar 7.a raw material yang belum di heat treatment menunukan bahwa fasa yang terbentuk adalah perlit dan ferrit. Setelah dilakukan proses harderning dengan suhu $845^{\circ} \mathrm{C}$ dan didinginkan secara cepat dengan air maka sudah mulai terbentuk strukutur mikro martensit yang ditunjukan pada Gambar 7.b. Pada tahapan terakhir yaitu pada proses tempering dengan suhu $200^{\circ} \mathrm{C}$ maka martensit sudah mulai berkurang. Pada kondisi ini kekerasan dan keausan baja sudah cukup baik yang ditunjukan pada Gambar 7.c. 


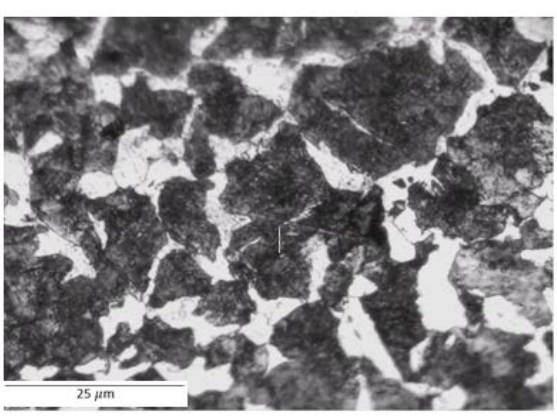

(a)

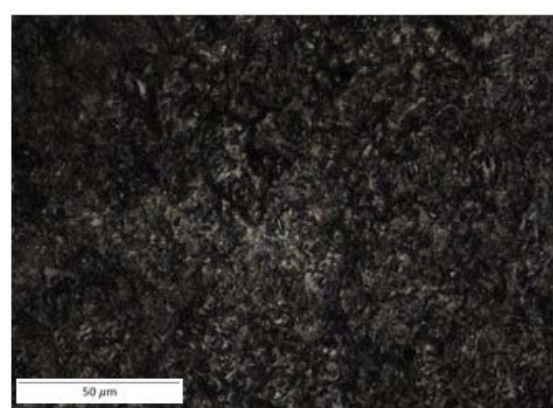

(b)

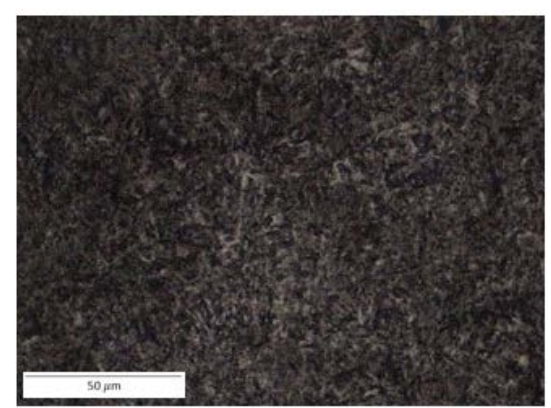

(c)

Gambar 7. Hasil uji mikrostruktur dengan masing-masing (a) raw material, (b) hardening dan quenching dengan media air, (c) tempering dengan pembesaran $200 \mathrm{X}$

\subsection{Hasil Uji Keausan}

Tujuan dari uji keasuan adalah mengetahui laju keausan material sebelum dan sesudah diheta treatment dan membandingkan dengan nilai kekerasanya. Berikut ini adalah tabel 6. uji keausan dan Gambar 8. Grafik perbandingan nilai kekerasan dan laju keausan.

Tabel 6. Uji keausan

\begin{tabular}{cccc}
\hline Heat Treatment & bo $\mathbf{( m m )}$ & $\left.\mathbf{b o 3} \mathbf{( m m}^{\mathbf{3}}\right)$ & $\mathbf{W s} \mathbf{( \mathbf { m m } ^ { 2 } / \mathbf { k g } )}$ \\
\hline Sebelum & 0,051389 & 0,28125 & $2,39 \mathrm{E}+00$ \\
Sesudah & 00.45 & 0.091 & $5,37 \mathrm{E}-01$ \\
\hline
\end{tabular}

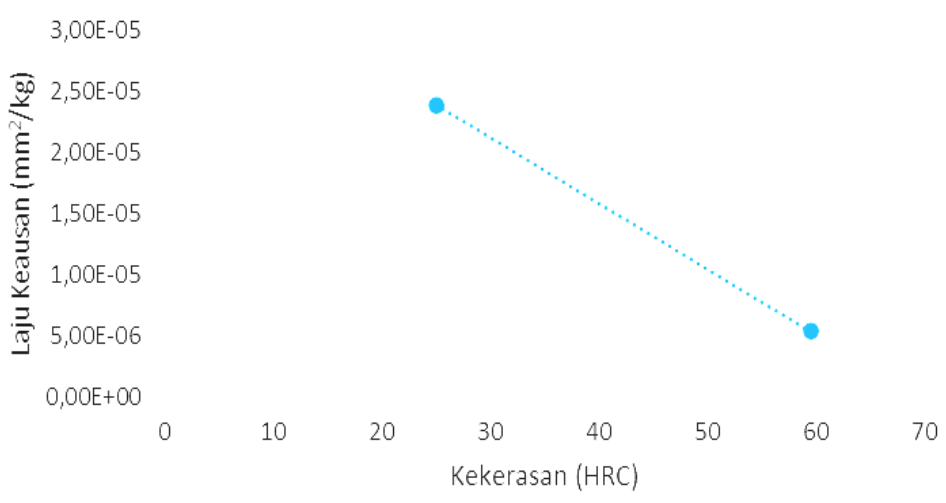

Gambar 8. Grafik hubungan kekerasan dan laju keausan

Dari grafik di atas menunjukan bahwa nilai kekerasan sebelum di heat treatment 25 HRC dengan kekerasan 25 HRC dengan laju keausan 2.39036E-05 setelah adanya heat treatment pada material dengan kekerasan 59,6 HRC adanya peurunan laju keausanya menjadi 5.37094E-06.

\section{Kesimpulan}

Dari percobaan menggunakan metode ANOVA menunjukan kombinasi dari hardening, quenching, tempering, dan waktu penahanan tempering berpengaruh dalam meningkatkan kekerasan yang dapat dilihat dari semua $\mathrm{F}_{\text {value }}$ lebih besar dari $\mathrm{F}_{\text {tabel. }}$. Sementara kontribusi terbesar dalam meningkatkan kekerasan adalan perlakuan quenching. Dari hasil eksperimen heat treatment yang dilakukan menggunakan metode taguchi maka kombinasi terbaik nya adalah sebagai berikut: hardening dengan temperature $845^{\circ} \mathrm{C}$, quenching dengan media pendingin air, tempering dengan temperature $200{ }^{\circ} \mathrm{C}$, waktu penahan tempering 60 menit. Hasil pengujian komposisi menunjukan nilai karbon tertinggi diperoleh dari material yang diteliti sebesar 0,48 dibanding produk yang ada dipasaran Hasil pengujian kekerasan menunjukan nilai kekerasan tertinggi diperoleh dari material yang diteliti sebesar 59,6 HRC dibanding produk yang ada dipasaran. Hasil dari pengujian mikrografi bahwa struktur mikro pada daerah pengerasan setelah di heat treatment masih mempunyai kekerasan yang cukup tinggi dan keuletan yang cukup baik. Hasil dari pengujian keausan plate on disk diperoleh nilai keausannya sebesar $2.39036 \mathrm{E}-05 \mathrm{~mm}^{2} / \mathrm{kg}$ menjadi $5.37094 \mathrm{E}-06 \mathrm{~mm} / \mathrm{kg}$ setelah dilakukan heat treatment. Hubungan antara kekerasan dan keausan dimana semakin tinggi nilai kekerasanya maka semakin berkurang keausan pada material dapat dilihat kekerasan sebelum di heat treatment 25 HRC yang keausanya $2.39036 \mathrm{E}-05 \mathrm{~mm} / \mathrm{kg}$ kemudian setelah di heat treatment nilai kekerasanya 59,6 HRC yang keausanya 5.37094E-06 mm²/kg. 


\section{Daftar Pustaka}

[1] J.E. Fernández, R. Vijande, R. Tucho, J. Rodr'1guez, A. Mart'1n .(2001) :Materials selection to excavator teeth in mining industry. Journal Elsevier. Spain.

[2] Avner, H, S. (1974). Introduction to Physical Metallurgy. 2nd edition, New York; McGrawHill International Editions.

[3] ASTM E18 - 3, Standard Test Methods for Rockwell Hardness and Rockwell Superficial Hardness of Metallic Materials.

[4] I Leng, Y. (2013) Materials Characterization: Introduction to Microscopic and Spestrocopic Methods Second Edition. Wiley-VCH Verlag GmbH \& Co. Germany.

[5] Ogoshi High Speed Universal Wear Testing Machine Instruction Manual.

[6] ASTM G99-04 Standard Test Method for Wear Testing with a Pin -on Disk Apparatus. Philadelphia, PA : American Society for Testing and Materials.

[7] Stachowiak, Gwidon W. (2005). Wear-Materials, Mechanisms and Practice.John Wiley \& Sons, Ltd., West Sussex, England. 